


\section{Resenha do livro: FIGUEIREDO, Vanessa Gayego Bello; RODRIGUES DA SILVA, Ronaldo. Paranapiacaba, um patrimônio para a humanidade. São Paulo: Editora Marquise, 2014.}

\section{Larissa Lohmann}

Arquiteta e Urbanista, Mestranda em Estudos Avançados em Arquitetura - MBArch Departamento de Urbanismo y Ordenación del Territorio, Universitat Politècnica de Catalunya

\section{TRADUZINDO O GENIUS LOCI DE PARANABIACABA}

Vanessa Figueiredo é arquitecta e urbanista, doutora (2014) e mestre (2015) em planejamento urbano e regional pela FAU USP (Faculdade de Arquitectura e Urbanismo da Universidade de São Paulo) e docente na FAU PUCC (Pontifícia Universidade Catòlica de Campinas). Integra o Comitê Brasileiro do $\mathrm{TICCIH}$ The International Committee for the Conservation of the Industrial Heritage. Foi Subprefeita de Paranapiacaba (2005-2007) e coordenadora de programas na Prefeitura de Santo André (2001-2004).

Ronaldo André Rodrigues é bacharel em Engenharia Elétrica pela PUC Minas (1989) e em Administração pela UFMG (1994); Mestre em Administração pela UFMG (1999); DEA em Sociologia (2003) pela Universidade Complutense de Madrid, Espanha (UCM) e Máster em "Conservación y Restauración del Patrimonio Arquitectónico y Urbano" (2007), pela Escuela Técnica Superior en Arquitectura de Madrid / Universidad Politécnica de Madrid (ETSAM/UPM). Docente da PUC Minas Gerais; fundador e actual presidente do Comitê do TICCIH-Brasil e integrante do TICCIH internacional.

3a Patamar dos Novos Planos Inclinados da Serra. Coleção: Artistides de Oliveira. Fonte: Aristides de Oliveira. Acervo: MSAOAG
Lugar onde se vê o mar. A tradução na linguagem indígena dá nome ao lugar que nos é apresentado no livro Paranabiacaba, um patrimônio para a humanidade. Sugere de princípio uma região curiosamente mesclada, de serra imponente, diversa como propõe desde os prelúdios as terras brasileiras, e com um peso histórico que um lugar como Paranabiacaba pode carregar.

Nos primeiros capítulos da obra, os textos nos revelam a história, os valores e as riquezas naturais singulares de uma região interiorana paulista, que nasceu e se desenvolveu como vila ferroviária em meados do século XIX, em plena ascensão da economia cafeeira no país. A Estação Alto da Serra, implantada no topo da Serra do Mar, possibilitava a ligação entre o interior paulista e o porto de Santos, tornando-se um ponto chave para o desenvolvimento da indústria do café de São Paulo. De um ponto de referência para este novo complexo ferroviário que surgia, junto a um considerável esforço humano e tecnológico em tornar viável a São Paulo Railway, uma nova comunidade se pronunciava ( o "povo dos trilhos", como amavelmente descreve Victor José Ferreira), e com ela uma necessidade de urbanizar aquela região. Neste cenário ilustrado pelo livro, personagens importantes para Souza, o 'Barão de Mauá ', que viabilizou a implantação da ferrovia graças a sua forte relação com capitalistas ingleses. o desenvolvimento da economia desta região são lembrados, como Irineu Evangelista de 
Os textos primam pela clareza em defender a multiplicidade e valor das estruturas ferroviárias, urbanas e sociais que alçaram a vila. O soar das rodas avançando nos trilhos, o espaço de encontros e desencontros, o controle do tempo, o abrigo, o movimento de passageiros, todos esses elementos se traduzem em signos que determinam a identidade deste lugar. A primeira ocupação urbana se denominou Vila Velha e se organizou ao longo de um eixo principal próximo aos depósitos e armazéns da empresa. Na encosta da colina, se formou um conjunto urbano de pequenas casas e comércios, configurando a Parte Alta ou Morro, uma ocupação compacta e marcada pela influência do período colonial português.

Vencidos os primeiros e árduos desafios da implantação da ferrovia, principalmente com relação a condição íngreme e úmida própria da Serra do Mar, o começo do século XX foi marcado pelo progresso de toda região, incluindo a Vila de Paranabiacaba no cenário econômico do estado. Os 'tempos modernos' se tornaram visíveis e, como resultado, a densificação exigiu que o número de residências fosse ampliado. Assim inaugurou-se em 1897 a Vila Martin Smith, implantada com padrões urbanísticos considerados bastante avançados para a época, com arruamento regular, redes de infraestrutura, espaços definidos

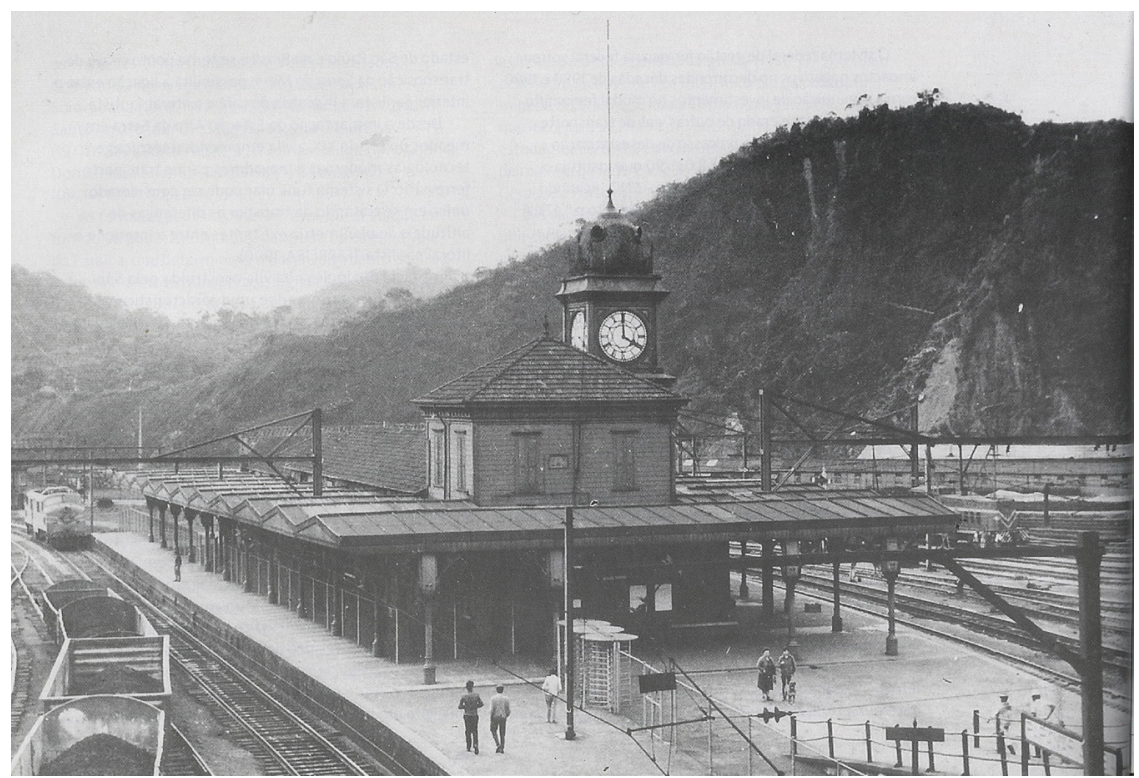

Segunda Estação Ferroviária de Paranapiacaba, 03/06/1968. Foto: Carlos Haukal Coleção: Foto Carlos. Fonte: Dalvira Ribeiro Cangussú. Acervo: MSAOAG 
para educação, lazer e comércio. Existia uma hierarquia funcional de ocupação, marcando sua clara intervenção inglesa, na qual identificava as categorias distintas de funcionários. A residência de maior destaque, por seu estilo arquitetônico residencial inglês e por estar situada em um sítio estratégico para a empresa, era conhecida como Castelinho e era destinada ao uso do engenheiro- chefe da companhia.

Nas últimas décadas do século XX, em função das modernizações implantadas no sistema ferroviário, a estação de Paranabiacaba foi perdendo pouco a pouco sua importância como estação, enfrentando um processo de desvalorização e abandono. Contudo, o silêncio que dissolvia um histórico tão rico foi quebrado por diversos grupos se que mobilizaram a buscar a preservação e tombamento da Vila, o que culminou em uma trabalho progressivo e na implantação de políticas públicas interessadas em garantir a recuperação e desenvolvimento sustentável da área.

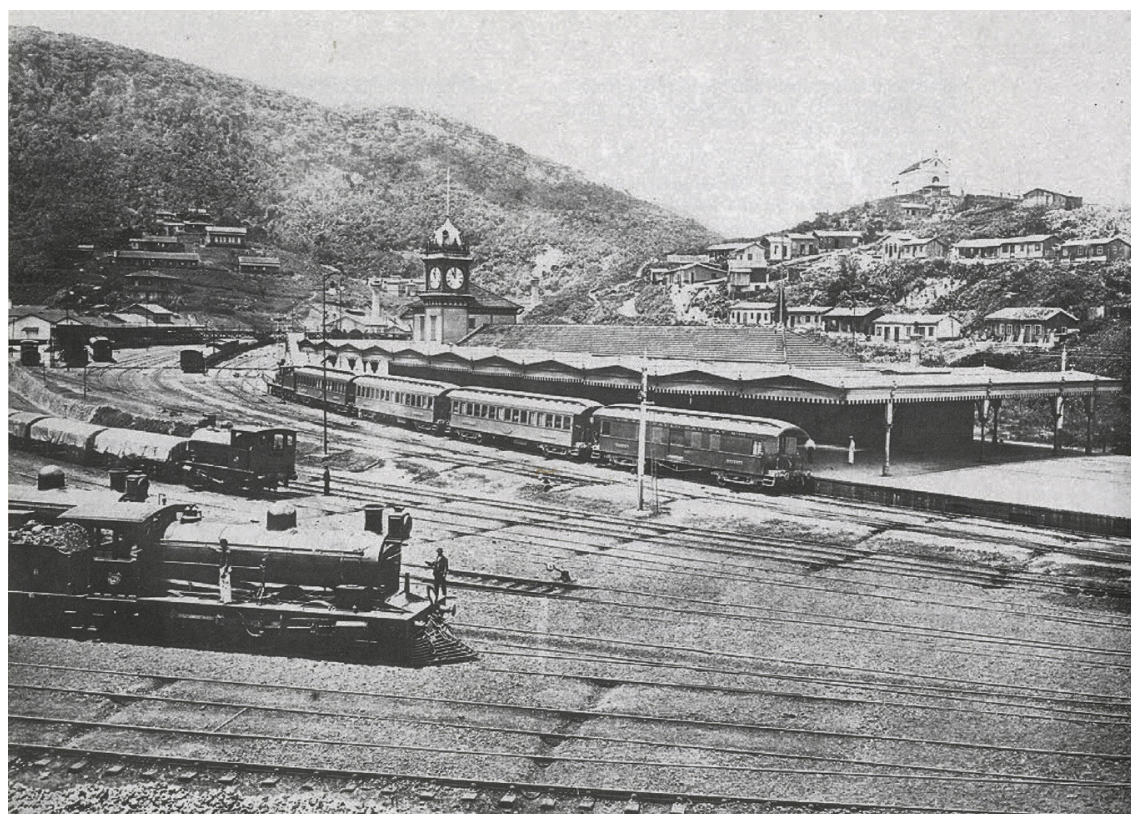




\section{DEFENDENDO UM PATRIMÔNIO MULTIDISCIPLINAR}

Tendo em vista os inúmeros matizes que compõe o patrimônio de Paranabiacaba, o processo de requalificação da Vila seguiu buscando soluções ante os desafios de transformar o contexto de descaso que sofria a área. A primeira resposta foi a descentralização administrativa, pois o isolamento e os problemas de mobilidade dificultavam a dinâmica entre a região de Paranabiacaba e a região central de Santo André. A estratégia da administração municipal procurava conciliar o desenvolvimento sustentável, a preservação ambiental e cultural e o turismo como atividade econômica. O fio condutor do subsequente Programa de Desenvolvimento Local Sustentável, criado em 2005, reformulou as estratégias adotadas, integrando ao novo programa de políticas públicas sete áreas: turismo, preservação do patrimônio cultural, planejamento urbano, conservação ambiental, desenvolvimento social, participação cidadã e gestão administrativo-financeira dos imóveis públicos.

Os últimos capítulos mostram que, paralelamente aos desafios entre preservação e planejamento, o projeto se preocupou em instalar no imaginário social a idéia de que recuperar a identidade da Vila permitiria o desenvolvimento econômico e sustentável da região, alterando a então cena de isolamento e abandono que dissolvia as riquezas de

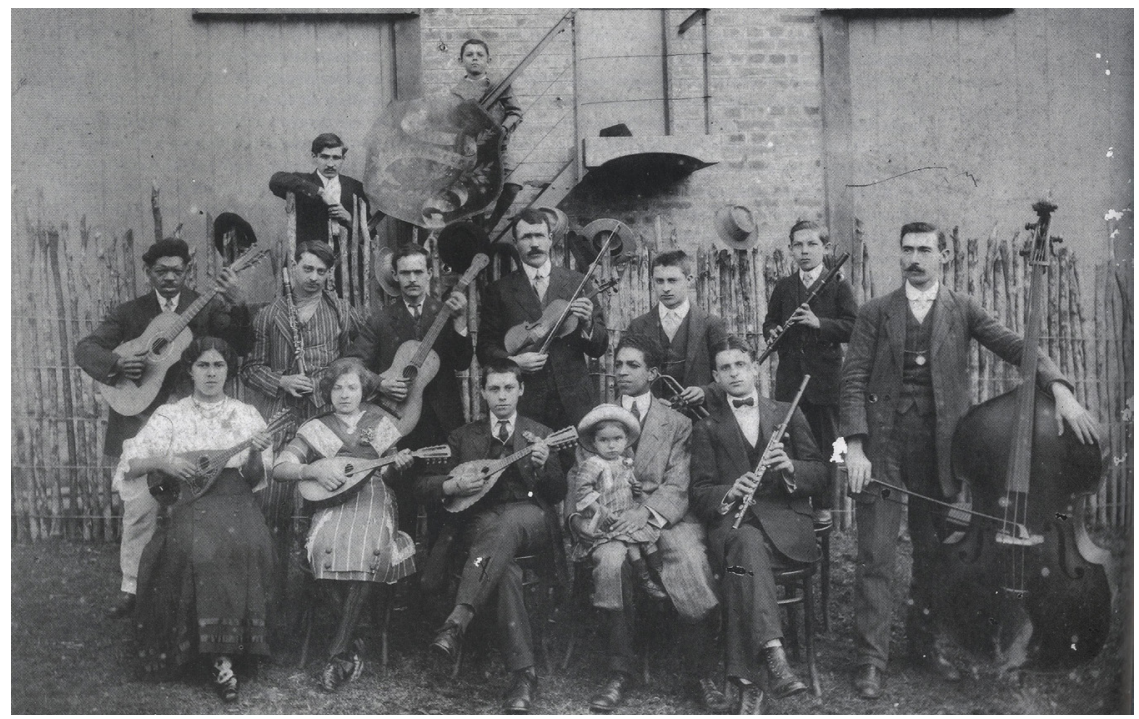

Grupo de músicos da Sociedade Recreativa Lyra da Serra, c. 1910. Col. e Fonte Claudete Carvalho Salvador. Acero: Museo de Santo André Dr. Octaviano Armando Gaiarsa 
Paranabiacaba. Os textos não deixam dúvidas quanto á máxima de que o exercício da cidadania foi o eixo estruturador das propostas, através de políticas que buscavam as vocações locais. A população participou, mesmo que em alguns momentos timidamente, de todos as fases do projeto e implantação, o que contribuiu muito para a construção de um sentimento de pertencimento, tão fundamental para o futuro que se espera para este patrimônio da humanidade.

\section{LEGADO DA EXPERIÊNCIA DE PARANABIACABA}

Entender Paranabiacaba como paisagem cultural passa pela compreensão de uma série de manifestações materiais e imaterias que o lugar emana; o lugar se expressa na tensão de seus elementos. O resultado da interação entre a intensa construção humana e o meio em que esta se desenvolveu constitui um tema relativamente novo. Carl Sauer (1925) estudou e propagou o termo paisagem cultural como o registro do homem sobre o território: "A cultura é o agente, o natural o meio, a paisagem cultural o resultado." Em outras palavras, podemos considerar o termo como um caleidoscópio formado pelo homem, sua cultura e seu meio natural, constituindo um sistema em constante evolução.

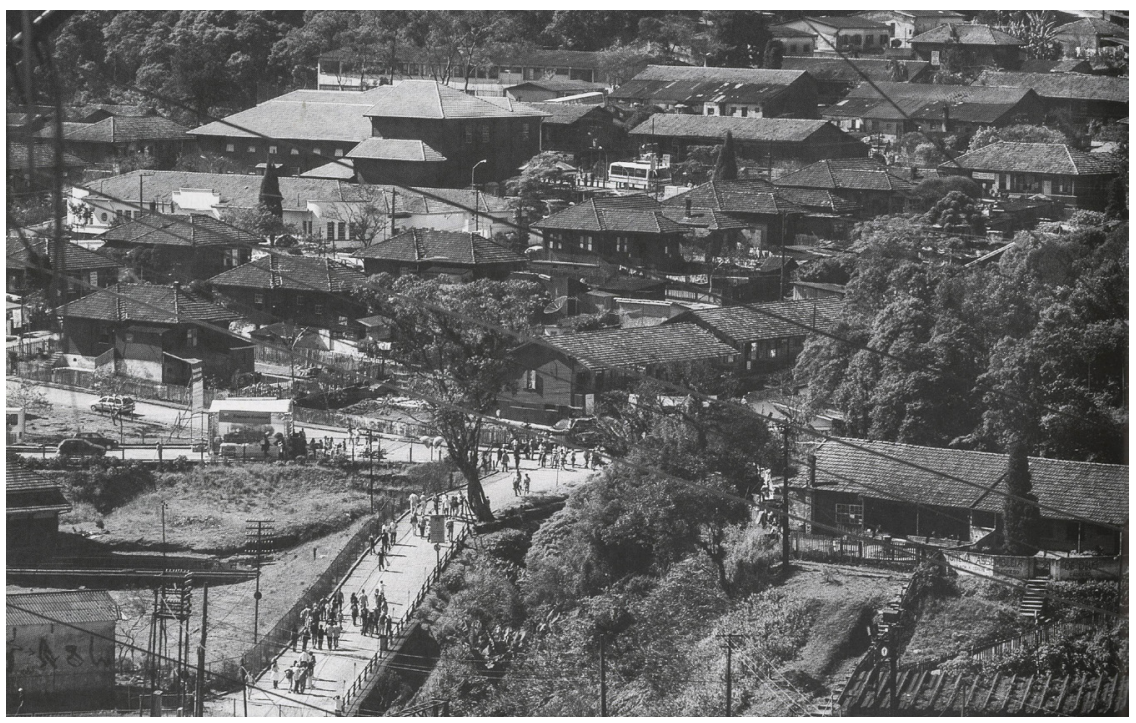


Ítalo Calvino, em seu livro 'Cidades Invisíveis', nos diz que existem diversas maneiras de falar de uma cidade. Uma delas é descrevê-la: dizer das torres, pontes, bairros e feiras. Neste mapeamento, a cidade desaparece como paisagem; uma simples panorâmica não revela a força do lugar composta por seus relevos, sua vida latente, suas tradições. O livro nos encaminha de maneira apaixonante para uma leitura de Paranabiacana não apenas descritiva. Os textos revelam muito mais que a descrição de sua estação ferroviária, seus galpões, clube e casas antigas. O denominador comum de todos os capítulos desta obra se trata de uma riqueza aquém á primeira vista de um estrangeiro: a visão de uma paisagem cultural singular que revela potencialidades ao interseccionar passado e presente. Torna claro ao leitor, a medida que o texto avança, que a força deste lugar não se trata apenas de seu valor como patrimônio, mas ao poder de combinar e reorganizar elementos históricos e atuais, através de uma gestão multidisciplinar, integrada e participativa.

O último capítulo do livro nos presenteia com uma série de depoimentos que reforçam a idéia de que "não há patrimônio sem humanidade". Nas palavras de antigos moradores e ferroviários, assim como de profissionais recém chegados e estudantes, se conclui que uma gestão inteligente se escreve não só com a cristalização de um patrimônio, mas principalmente no reforço da autoestima de uma comunidade, criando a base para a construção de um novo futuro. A Vila de Paranabiacaba, que concorre a Patrimônio da Humanidade pela UNESCO, já leva o triunfo de poder lançar uma luz, um caminho para uma mirada mais atenta ás inúmeras e ricas paisagens orgulhosamente brasileiras.

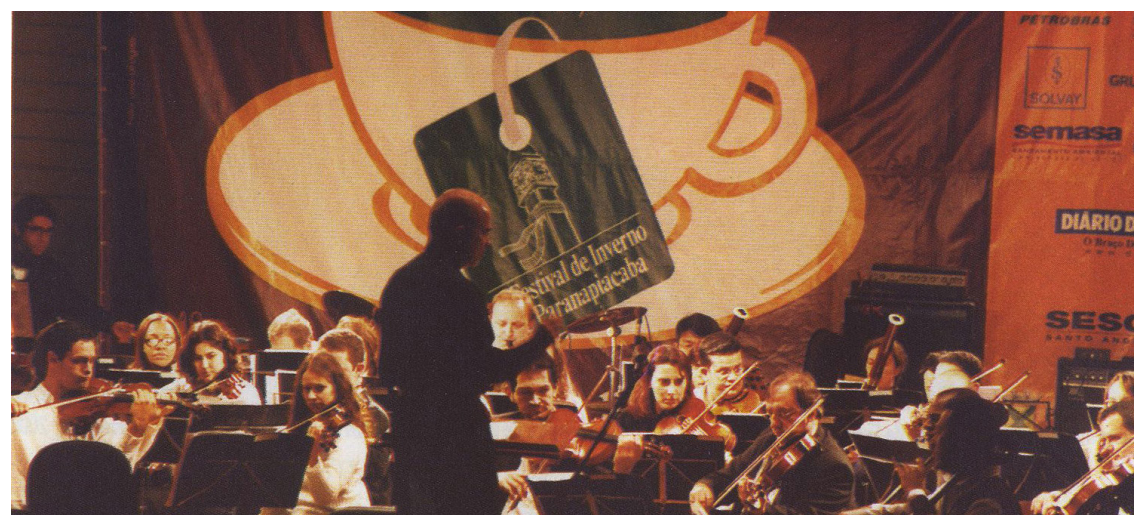

Apresentação da Orquestra no $4^{\circ}$ FIP - Festival de Inverno de Paranapiacaba. Foto: PMSA / Beto Garavello, 2004. 


\section{ID_RESENHAS DOS LIVROS}

\section{REFERÊNCIAS BIBLIOGRÁFICAS}

INOSTROZA, S. T. (2002). "Huellas en la ciudad heredada: Complejidad y continuidad en la morfogénesis del proyecto urbano contemporáneo". Barcelona. Tesis doctoral, UPC.

PEIXOTO, N. B. (2003). "Paisagens Urbanas”. Editora Senac, São Paulo.

SAUER, C. (1925). "The morphology of landscape”. En: Leighly, John (ed.). Land and life: a selection from the writings of Carl Ortwin Sauer. Berkeley: University of California Press, 1963 (texto original de 1925).

SABATÉ, J. e GALINDO, J. (2009). "El valor estructurante del patrimonio en la transformación del territorio". Em: Revista Apuntes, vol. 22, no1, Bogotá, enero-junio, pp. 20-33.

SABATÉ, J. (2005). "De la preservación del patrimonio a la ordenación del paisaje”. Em: Revista

Identidades: territorio, cultura, patrimonio, Laboratorio Internacional de Paisajes Culturales, no 1 Barcelona, pp. 15-33. 